\title{
Expectations and realities: Examining adolescent students' game jam experiences
}

\author{
Riikka Aurava $^{1}$ (D) $\cdot$ Mikko Meriläinen $^{1}$ (D)
}

Received: 14 June 2021 / Accepted: 8 October 2021 / Published online: 25 October 2021

(C) The Author(s) 2021

\begin{abstract}
This article describes the expectations and experiences of young (16 to 19 year old) digital game jam participants $(\mathrm{N}=34)$ who attend Finnish general upper secondary schools. Game jams are a form of game creation: events where games are made in co-operation. They are widely used in game design education and in addition, when participated voluntarily, learning has been reported as an important motivation. The existing literature mostly concentrates on game jams for adults, and informal or non-formal learning. This article is adding to the literature by examining learning in formal education for adolescents. As part of our research, we have organised game jams in formal general education, and this article is based on the pre-event and post-event surveys of three game jam events. The article maps 1) the motivations to attend a school related game jam, 2) the expectations and apprehensions the would-be participants have, 3) what kind of learning game jams promote, and 4) how does attending a game jam affect participants' attitudes and apprehensions regarding learning, STEAM and information technology, and their own skills. Our results indicate the creative side of digital game making, desire to learn new skills and make new friends to be the main motivations for participation, and the lack of confidence in technical skills to cause most anxiety before the jam event. The effects of attending a game jam are mostly positive, with the participants reporting learning experiences in several soft and technical skills and increased motivation to take part in creative and co-creative projects. A gendered result can be seen in the participants' altered stance on technology and programming: girls and non-binary students report technology and programming being easier and more fun than they had thought before attending a game jam event, which is well in line with previous research on STEM/STEAM education and gender.
\end{abstract}

Keywords Game jams · Creativity · Co-creation · STEAM learning · Adolescents · Gender inclusivity

Riikka Aurava

riikka.aurava@tuni.fi

1 Tampere University, Tampere, Finland 


\section{Introduction}

Game jams are condensed game co-creation events (Kultima, 2015) that are participated in for both leisure and learning purposes (see Preston et al., 2012; Arya et al., 2013; Kultima, 2019). They come in a multitude of formats (see Eberhardt, 2016), with some game jams being very short and intense efforts of only a few hours, whereas others go on for several days. Game jams are organised both onsite at physical locations and online, and most of them focus on digital game creation. Grounded in game development education, game jams are increasingly being used in other educational settings as well, from elementary schools to higher education. However, research on game jamming in formal general education and with adolescents is scarce, and research on the pedagogical dimensions of game jams has typically taken place in the context of education focused on game development (see Meriläinen et al., 2020).

Game jams are a particular type of game making event, and can be seen as an expression of a broader constructionist learning paradigm, in which learning happens through creating concrete artifacts (see Papert \& Harel, 1991; Kafai \& Burke, 2015). Game jams have been shown to promote learning and increase learning motivation and self-efficacy (see Background section), yet they have not been widely adopted as a learning method in schools. Game jam learning cannot be easily predicted or assessed, as the participants learn different things via their different roles in teams. Organising a game jam takes time and effort (Aurava et al., 2020b; Kankainen et al., 2019; Yamane, 2013; Locke et al., 2015), and curricula as well as teachers' lacking resources may hinder the adoption of a new learning method (Aurava et al., 2020b). Game jam participation in general is gendered (see Arya et al., 2013; Kerr, 2020), and when game jam events are organised for adolescents of all genders in educational settings, inclusivity is especially important.

There is limited research on the game jam experiences of teenage participants (see Fowler et al., 2016; Arya et al., 2019), studies having commonly addressed older jammers (see Arya et al., 2013; Hrehovcsik et al., 2016). This is in part due to a considerable part of the literature focusing on either students studying game development in higher education, or the Global Game Jam events, which have a minimum age limit of 18. The previous research on teenage participants focuses mostly on informal learning situations (see Fowler \& Khosmood, 2018), and there have been few attempts to organise game jams as part of school activities (however, see Ford \& Kelly, 2016).

Our study addresses this gap in the literature by exploring the expectations and apprehensions that teenaged (16-19) game jam participants have before a game jam, as well as how these expectations are matched by the actual event. By charting the expectations and comparing them to reported outcomes, we gain new insight into the game jam process and individual experiences, specifically in an educational context. Adopting a qualitative approach enables us to gain relevant and nuanced information from a limited number of participants.

If game jamming is to be adopted as a learning method, information is needed on how participants view game jam events and their possible impacts on learning, as 
well as participants' reasons for attending or not attending, and any apprehensions they might have about game jamming. Increased knowledge on what hinders or promotes participation in game jams, as well as what aspects of game jam events have an impact on learning, is crucial when designing game jams for learning. Identifying potential issues in advance enables game jam organisers to better plan their events, whether they're organising jams for learning or leisure. With organisers aware of possible problems, steps can be taken to ensure a safe and enjoyable game jam environment conducive to learning and participant well-being.

\section{Background}

Existing research strongly suggests that learning happens during game jams (see Meriläinen et al., 2020 for a review). In addition to learning game creation and development skills (e.g. Faas et al., 2019) and STEAM (Science, Technology, Engineering, Arts, Mathematics) skills (e.g. Pollock et al., 2017), development of socalled soft skills, such as communication skills, organisational skills and learning skills, has been suggested in previous literature (e.g. Fowler et al., 2016; Preston et al., 2012; Smith \& Bowers, 2016). Learning, especially of technical game creation skills, has also been widely reported as a motivation to attend game jam events (Arya et al., 2013; Fowler et al., 2013; Smith \& Bowers, 2016; Wearn \& McDonald, 2016). Teacher views on game jamming in schools have not been widely researched, but at least one study of Finnish teachers (Aurava et al., 2020b) found that teachers saw game jams as a pedagogically valuable method for learning especially communicational and cooperational skills. While measurement of learning, especially of so-called soft skills, remains an issue (e.g. Devedzic et al., 2018; Gibb, 2014; Meriläinen et al., 2020), respondents in both qualitative (e.g. Meriläinen, 2019) and quantitative (e.g. Arya et al., 2013) studies have reported experiences of learning as well as increased self-efficacy.

Game jam learning has several connections with twenty-first century skills, competencies that are generally seen as useful qualities or learning goals for the postindustrial society, in which the demands of working life are rapidly and constantly transforming. twenty-first century skills include both intra- and interpersonal skills, like time management, learning to learn skills, communication skills, and creativity, with the educational goal of bringing up individuals who can thrive in contemporary society. They also reflect the change towards information society, including skills like media, information and technology literacies (Binkley et al., 2012; European Union, 2006; OECD, 2012, 2013; Trilling \& Fadel, 2009). In digital game jams, the ICT literacy and practical skills in computer programming are furthered. Educational research and practice communities are trying to find ways to support these skills (Ananiadou \& Claro, 2009; Lavonen \& Korhonen, 2017), and educational game jams provide one promising avenue. Game jam learning closely relates to such collaborative and process-oriented methods as collaborative knowledge building and creation (Paavola et al., 2004; Scardamalia \& Bereiter, 2014), digital fabrication and maker-centred learning (Blikstein, 2013; Kafai, 2006; Riikonen et al., 2020), 
phenomena based learning (Lonka et al., 2018), project-based learning (Krajcik \& Shin, 2014).

Ideally, game jams provide a safe and playful environment for experimentation, with few ramifications for mistakes or failure (see Goddard et al., 2014; Kultima et al., 2016; Meriläinen, 2019). Different constraints such as time may reinforce this: as a commercial game usually takes months or years to complete, participants cannot expect to achieve something similar in a single weekend, let alone one evening. This has been suggested as a reason why game jams support and bring about learning (Meriläinen, 2019; see also Arya et al., 2013). However, a safe and relaxed environment does not automatically appear, but requires a conscious effort by game jam organisers (Kultima et al., 2016; Kultima \& Laiti, 2019; Kankainen et al., 2019; Kerr \& Savage, 2019).

The time constraints and hectic pace of a game jam can run the risk of enforcing or glorifying crunch culture present in the game industry (e.g. Borg et al., 2020; Kennedy, 2018), although it has also been suggested (Borg et al., 2020) that game jams provide organisers the opportunity to challenge and problematise crunch culture. Crunch culture refers to a much-criticized labor practice of working unpaid for overtime, to speed up projects (see e.g. Peticca-Harris et al., 2015; Cote \& Harris, 2020), and while the problem has been identified, it seems to persist (Legault \& Weststar, 2017). Crunch culture is especially discriminating against women (Consalvo, 2008) or others with caring responsibilities (Legault \& Weststar, 2017). Game jam events have been suggested to serve as a bridge between formal game development studies and work in the gaming industry (e.g. Hrehovcsik et al., 2016), and often mirror the industry in that they are frequented by young white men, if there is not a conscious effort for inclusivity by the organisers (Ferraz \& Gama, 2019; Kennedy, 2018; Kerr, 2020; Kerr \& Savage, 2019, 2020).

Game design industry is dominated by male professionals. Furthermore, the tasks are highly gendered, with women most often working on art and animation and men on programming and other engineering roles (Bailey et al., 2021; Prescott \& Bogg, 2011). On even bigger scale, women and non-binary persons are underrepresented in STEM (science, technology, engineering, mathematics) studies and careers (e.g. Chen et al., 2017). The gender gap is created at an early age (Jacobs et al., 2002), and while there have been several attempts at getting girls interested in programming and other STEM studies and careers (e.g. Corneliussen \& Prøitz, 2016; Makarova et al., 2019; Sigurðardóttir, 2020), girls are less likely than boys to enroll in STEM studies (Appianing \& Van Eck, 2015; OECD, 2021), and more likely to drop out of them (Ellis et al., 2016) and girls' interest in STEM subjects (Gaspard et al., 2017), STEM careers (Saw et al., 2018) and their confidence in their own STEM related abilities (Jacobs et al., 2002; Nagy et al., 2010) decline during adolescence. Integrating creativity (Arts) in STEM education, making it STEAM education, has been offered as a solution to attract a more diverse group of individuals (Land, 2013; Piro, 2010; Richard et al., 2015; Walan, 2021). Game jams, and game design more broadly, is an example of a STEAM approach: several artistic skills like drawing or making music are as needed in the industry as programming, and it should be noted that these are typically also performed using digital tools, challenging a clear delineation between technological and artistic skills. Furthermore, game 
design and programming can also be seen as creative endeavours (Peppler \& Kafai, 2005; Romero et al., 2017) and game making has previously been shown to increase learning motivation (Cheng, 2009).

While game jams are typically enjoyable, voluntary events for most participants, taking part in a jam can be stressful before or during the event, especially for firsttime jammers. Before the event, participants may for example be unsure about their skills and expertise in comparison to others, whether they connect socially with other jammers, and if they can finish a game during the event (Meriläinen \& Aurava, 2018; Savvani, 2020). If they are coming to their first game jam, they may not have a clear idea of what a game jam event consists of. This can be a barrier to entry, especially for adolescents (Aurava et al., 2020a). Participant apprehensions can be alleviated by providing more information as well as with workshops, introductory events and various means of social and financial facilitation (Kerr et al., 2020; Kultima et al., 2016; Meriläinen, 2019), for example. During the jam, social conflicts, unmet expectations or disappointment for not meeting self-set or group goals can cause negative experiences (see Steinke et al., 2016; Kultima et al., 2016). After a jam, however, many jammers report overall positive experiences of learning and increased self-efficacy (Kultima, 2019; Meriläinen, 2019; Miller et al., 2019; Savvani, 2020). In other words, the anxiety decreases during the jam event and negative expectations experienced before the jam often turn out to be unfounded. However, the existence of these apprehensions suggests that some potential participants likely do not attend game jam events despite wanting to.

\section{Data and methods}

In this qualitative study, we examine the pre-jam expectations $(\mathrm{N}=34)$ and post-jam reflections $(\mathrm{N}=27)$ of adolescent (aged 16-19, $\mathrm{M}=16,85)$ game jam participants based on three game jam events organised in Finland for general upper secondary school students between January 2018 and March 2020. Of all participants to the pre-event survey, $43 \%(\mathrm{~N}=15)$ identified as girls, $34 \%(\mathrm{~N}=12)$ as boys, and $20 \%$ $(\mathrm{N}=7)$ as non-binary, while $3 \%(\mathrm{~N}=1)$ did not disclose this information. Other demographic factors were not recorded. For example, ethnicity and parents' education or income were left out of this study. Ethnic background is not recorded in Finland, so the only way of tracing that would be participants' first language or citizenship, which in themselves are not reliable or accurate indicators of ethnicity. Of the students in all Finnish general upper secondary schools in the academic year 2021-2022, 6.7\% did not have Finnish, Swedish, or Sàmi (the official languages in Finland) as their first language, and 3.5\% were not Finnish citizens (Finnish National Agency of Education, 2021a). In comparison, by the end of 2020, the overall percentage of foreign-language speakers in Finland was $7.8 \%$, and $5 \%$ of the population were not Finnish citizens (Statistics Finland, 2021). The study data consists of responses to questionnaires primarily made up of open-ended questions, allowing respondents to formulate their own answers rather than confining them to predefined ones, thus better reflecting their lived experience (see Braun et al., 2020). The research questions are as follows: 
Q1. What kinds of expectations and apprehensions do students have prior to attending a school related game jam event?

Q2. How does participation in a school related game jam affect students' perception of their skills and abilities?

Q3. What other effects do school related game jams have on the participants?

The survey questionnaires we used (see Appendix) were formulated based on two premises: the broader goals of the research project this article is a part of Growing Mind research project, which aims to develop teaching and learning in Finnish schools (Growing Mind, 2021), and our takes on the previous literature of game jam participants and learning (Meriläinen et al., 2020). The purpose of the surveys was also twofold: we needed knowledge of the participants for practical reasons, to aid us in organising the events, and for our research. In the pre-event survey, we explored the participants' prior experience on making games, motivations for participation, and to come to our event, their perception of their skills, and their overall relationship with games. The post-event surveys charted the participants' experiences of the jam: what skills they had used and learned, perceived changes in skills, and cooperation with other jammers. We also asked for feedback on the event itself. After the first jam event, we reformulated some of the survey questions, mostly by splitting one question into two, in order to make them easier for the participants. Questions 7 and 9 of the pre-event survey were dropped after the first event due to the different approach regarding tools and software in the latter two events, and the question regarding participants' hobbies was moved from post to pre-event survey for the latter two events.

To describe the overall expectations and outcomes of the participants, we use data collected from all the participants (pre-survey $\mathrm{N}=34$, post-survey $\mathrm{N}=27$ ). As all participants did not complete the post-jam survey, when comparing the results from both pre- and post-survey, we use paired data from participants that answered both surveys $(\mathrm{N}=26)$. Data was paired using anonymous personal identifiers constructed by the participants.

The analysis method chosen for this study is thematic analysis, in which data is examined to identify broader themes (Braun \& Clarke, 2006). As we were addressing a subject with limited previous research, we adopted an exploratory approach, in which our interpretation and analysis of the data did not follow a predefined theory frame. We familiarised ourselves with the data set by carefully and iteratively reading and re-reading it both before and during the analysis. We both then independently coded the whole data. Next, we compared and discussed our coding until agreement on codes and interpretations was reached. Codes were then sorted into subthemes, which were in turn used to construct wider themes.

Through this process of coding, interpretation and discussion, we constructed the main themes of Learning new skills, Creativity and self-expression, Social dimensions, Technology, and Personal relation to games and game culture. We discuss these themes in detail in the results section. 


\subsection{Events and participants}

All three game jams were organised as part of schoolwork and in cooperation with schools. All schools were general upper secondary schools in major Finnish cities. In the Finnish school system, all pupils enter the primary (age 7-12) and lower secondary schools (age 13-16). After that, they can apply to enter either vocational or general upper secondary school, of which the latter has traditionally been seen as a path to higher education. The general upper secondary school lasts for two to four years, with the majority of students graduating after three years. (Finnish Ministry of Education \& Culture, 2020) In our first jam event, the invitation was sent to students of three schools, whereas in the other two events, the invitees were all students of one school. Both of these schools focused on performing arts. This was not intentional: the collaborating teachers, who were existing contacts, happened to work in these schools. The students received study credits for participating.

We designed the invitations to our game jam events so that they would be as inclusive as possible, highlighting the need for a variety of skills like writing, drawing, and making music, rather than prioritising skills such as programming and game design. By doing this, we wanted to promote a STEAM (Science, Technology, Engineering, Arts, and Mathematics) approach rather than a STEM (lacking the Arts aspect) one (see Bequette \& Bullitt Bequette, 2012; Land, 2013; also Meriläinen et al., 2020). In addition, we offered all participants a workshop or tutoring on game design software and programming, to lower the threshold for would-be-participants who were anxious of their ICT skills. We did also offer sponsored laptops and other tools for the duration of the jam to lower the threshold of participation for those with financial problems, although all students of Finnish upper secondary schools have their own laptops. The digital game development tools used were free and did not require to be downloaded, which makes them usable for the participants even after the jam event.

Although we strove for inclusivity, we did not specifically address gender in our communications. The invitation was signed by the organisers, and one of the names was a typically feminine Finnish name. The invitation was formulated to be both informal and approachable in style and informative in content. In the invitation, we expressed that no skills whatsoever were needed to attend, and that interest in the event was enough. We told them that no tools or personal computers were needed, and that we would offer food on-site, to relieve any tension regarding the economic status of the would-be-participants. In addition, we explicitly framed the event as non-competitive and focused on co-creation. (For more information on making game jams more inclusive and diverse, see also Kerr et al., 2020, and anonymised for review purposes.) With this kind of invitation, we had 15 girls, 12 boys, and 7 non-binary students in our jam events. The result of the gendered distribution is encouraging but it needs to be noted that girls form the majority (58\%; Official Statistics of Finland, 2020) of Finnish general upper secondary school students and that two of the jam events were organised in schools that specialize in art education, with an even higher percentage of girls and plausibly also non-binary students than the average. Official Statistics of Finland does not recognize more than two genders and does so based on a person's social security number. In our study, we asked which 
gender the participants identified as. Although we cannot be sure of how or whether our invitation impacted participant demographics, previous research (e.g. Ferraz \& Gama, 2019; Kerr et al., 2020) suggests that event communication plays an important role in inclusivity.

The first game jam was organised in November 2018 in Tampere, and the invitation went out to $800+$ students in three schools. We ended up with 9 student participants, of which 8 ( 3 girls, 5 boys) elected to take part in the study (for barriers to student attendance, see Aurava et al., 2020a). All participated in the pre-survey, while 7 students took the post-survey. The jam went on for $48 \mathrm{~h}$, from Friday afternoon to Sunday afternoon, with approximately $18 \mathrm{~h}$ spent on-site. The jam site was a communal playful learning environment at Tampere University. The theme for the jam was the word lähde which has several meanings in Finnish ('a spring', 'a source', and imperative form 'go' or 'leave'), and the participants finished three games. The games were made using the Unity game making engine (Unity technologies, initial release 2005), which was requested by the participants themselves. There was no prior workshop, but the basics of Unity were taught to willing participants by an experienced game jam hobbyist on the first day of the jam event.

The second game jam was organised in December 2019 in Helsinki, and the invitees were students of one school only, a group that had chosen creative writing as an optional course. The jam site was a classroom in their own school. All students used the Twine platform (Klimas, initial release 2009), designed for making narrative games with branching storylines. As a theme, we used the letters $\mathrm{H}$, I, and $\mathrm{O}$-in whatever order or combination the participants chose to interpret them. In Finnish, the letters can be arranged to form at least five different words, with vastly different meanings (e.g. ohi means past, while iho means skin). We had an additional constraint to the games made in this jam, which was added by the collaborating teacher guiding the school's creative writing classes: the games needed to address a current social issue. We had 16 participants ( 8 girls, 4 boys, 3 non-binary, one undisclosed) in the jam event. We organised a separate two-hour Twine workshop two days prior to the jam, teaching all the participants the basics of the game engine. As part of the workshop, we had a lecture from a narrative designer working at a prominent Finnish game studio, discussing the importance of game narratives and work in the game industry. As women are severely underrepresented in the game industry (Neogames, 2019) and the majority of our participants were girls, we specifically chose a female professional as our guest speaker. The jam event itself ran for six hours during one afternoon and evening, resulting in four games. 15 students took part in the presurvey, and 12 students took part in the post-survey, including one student who did not take part in the pre-survey.

The third jam was organised at the turn of February and March 2020 in Turku, and the invitees were the students of one school. This time we were not the main organisers: a teacher at the school organised the practicalities and recruited the participants. The event site was a combined multimedia library and social space in their own school. We were mentoring the organiser during the whole process and were onsite during the game jam event. This event ran for $48 \mathrm{~h}$, from Friday afternoon to Sunday afternoon, with approximately $15 \mathrm{~h}$ spent at the jam site. There was also a voluntary two-hour workshop before the jam event, in which the participants were 
guided through a tutorial in Construct (Scirra, initial release 2011), the primary game engine recommended to the groups. The theme for this jam was a musical composition: Nikolay Rimski-Korsakov's The Flight of the Bumblebee. There were 11 participants in the game jam (4 girls, 3 boys, and 4 non-binary) with four games finished at the end of the event. 11 students took part in the pre-survey, and 8 students took part in the post-survey.

Teams were formed in the beginning of every jam event, after initial presentations, the announcing of the jam theme, and ideation based on the theme. The teams were formed partly based on similar interests, partly on existing friendships, and the formation process was relatively easy, with the organisers offering suggestions and support when needed. Teams typically consisted of three to five students. In the first jam event, one participant worked mostly on their own game, thus forming a group of one. Despite this, they also worked alongside other teams and interacted with other participants throughout the event.

\section{Results}

The results are presented according to the six main themes in the data: Learning new skills, Creativity and self-expression, Social dimensions, Technology, Personal relation to games and game culture, and Confidence and self-efficacy. These themes are distinct, yet inevitably have some overlap: for example, the motivation to learn can relate to learning technology or social skills, and creativity can often tie in with the participant's relation to game culture. Additionally, themes include both barriers and motivations to entry, as the same aspect of a game jam can motivate some participants and intimidate others.

\subsection{Learning new skills: "Usually good things are born outside the comfort zone”}

This theme encompasses the dimension of skills and learning in game jams. In line with previous research, all the participants wanted to learn at the event, with some of the participants having more defined learning goals than others. During the event, the skill repertoire of the participants grew, and in the post-survey most participants reported they had learned several skills: the most commonly mentioned were technical and social skills. Furthermore, several participants reported increased confidence in their own skills and increased levels of creativity. Motivation to learn even more after the jam event was also widely reported.

In the pre-event surveys several participants mentioned the urge to try new things and learning also came up as a motivation to attend the event. This is in line with previous research, where learning has been identified as a major motivation to attend game jams (Arya et al., 2013; Fowler et al., 2013; Smith \& Bowers, 2016; Wearn $\&$ McDonald, 2016). However, in our data, creativity and general interest in games were more common reasons to attend the events than learning. 
Making games and programming have always fascinated me, so I thought this would be a good opportunity to try [them], even though I do not know much. (girl, event 2, ID 14)

[I wanted to attend the jam because it is] a new experience and a good opportunity to learn new things. (girl, event 3, ID 33)

Lack of skills and knowledge, whether actual or perceived, can also be a barrier to entry (Meriläinen \& Aurava, 2018; Faas et al., 2019; Aurava et al., 2020a). The fear of not having adequate skills was the most often mentioned cause of anxiety in our pre-event surveys. Additionally, some participants experienced anxiety because they felt they did not know enough of games in general or because they lacked knowledge of the event and game jamming in general.

[I am] perhaps nervous about whether I will fit in and will I know game related things, because the world of games is not very familiar to me. (girl, event 2, ID14)

My IT skills aren't top notch, and I have no previous experience. (girl, event 2, ID 16)

Although learning as a primary motivation to take part in a game jam was not prevalent in our data, all of the participants had something they wanted to learn in the game jam, with some articulating their learning goals more specifically than others. Of the learning goals, most often mentioned were to learn the process of game making and the different areas of expertise required in it and to learn how to code in general or to learn how to use the software for making games. Several participants also claimed that they wanted to learn "everything" or "new skills" in general, while some found it hard to answer the question since they did not know enough of the subject.

I would like to learn more about the process of game making and how to make a game from beginning to end. (boy, event 1, ID 01)

[I want to learn] more about coding and how game making in general happens from the beginning (nonbinary, event 3, ID 26)

Of the self-reported skills before the jam events, most often mentioned were drawing or graphics, writing or creating stories, and coming up with ideas. Of the 26 students who participated in both pre- and post-surveys, eight ended up doing things they already had skills in. Another eight reported additionally doing other things than they initially thought they could do, with ten more doing new things they had specifically told they wanted to learn. Our interpretation is that while roughly a third of the participants stayed in their comfort zone, the majority of the participants engaged in activities new to them.

I took part in designing with the team, edited one picture with drawing software, searched for music and pictures (additionally, I commented and took part in the writing process of the game every now and then) I had not planned to do so much, I had thought I would be sitting confused in the sidelines (girl, event 2, ID 13) 
The most often mentioned activity that was completely novel for the participants was coding or using the game making software. For some, it had been a self-defined learning goal, and for others, it was just an addition to their repertoire. Additionally, some participants were doing creative tasks they had not previously reported skills in: drawing, making music or writing the plot for the game, while some reported they had been responsible for organising the group work and supporting other participants.

I coded, and made music and a bit of the graphics. I had prepared to do all of these, but mostly music. (nonbinary, event 3, ID 27)

Only four participants claimed they had not learned anything new during the jam event, with two of them reporting that they had realized they had better skills than they initially thought and two claiming that their perception of their own skills had not changed, either. Some of our participants did not specify which new skills they had acquired, or which skills improved. Of the more specific replies, some trends could be identified. The most often mentioned were 1) new or improved technical skills, like coding or using software; 2) improved social skills; 3 ) improved organisational skills like time management. There were also some mentions of learning the process of making games, increased level of creativity, and increased level of confidence in own opinions and skills.

Mostly my technical skills improved for the better. Before, I did not have any experience in programming. Now that I have taken the first step I have been searching YouTube for videos that teach programming. (boy, event 1, ID 08) Teamworking skills progress with every experience, so I feel that this too gave new experience in that field. I also learned a little programming, and how a game is created so called from nothing. Additionally this project might have emphasized that new things are worth trying out, even if one does not have any previous experience. Usually good things are born outside the comfort zone. (girl, event 2, ID 20)

\subsection{Creativity and self-expression: "I've loved creating my own fictional worlds ever since I was a child"}

Creativity was the second most often articulated reason to attend our game jam events. Making games was seen as a creative endeavor (see Kultima \& Sandovar, 2016), which was a major motivation to attend the game jam. The emphasis on the creativity and self-expression aspects in our data is likely to a degree explained by our sample, as two of the three jams examined took place in general upper secondary schools specialising in performing arts, and the invitations highlighted several creative skills needed in game making. Many of the respondents described themselves as creative and imaginative.

I like video games. I am a creative person who likes to create new things. (nonbinary, event 3, ID 27) 
In the game world you can create your own rules and ways of acting without limitations, and I've loved creating my own fictional worlds ever since I was a child. (girl, event 2, ID 16)

Games were seen as art by many participants, with some participants explicitly calling games an art form. Other respondents highlighted individual aspects of game creation, such as creating graphics or writing stories. Although coding can be seen as an avenue of creativity and self-expression (Dufva \& Dufva, 2016), this aspect did not come up in the answers.

I've played a lot ever since I was young, and I admire games as a form of art. It would be awesome to be able to bring out my own ideas in game form. (girl, event 3, ID 32)

The interactivity inherent in games was seen as a distinguishing feature compared to traditional media or art, and the experience of gameplay was emphasized.

The ways for self-expression are more multidimensional [in games]. In a traditional written story you follow a linear path of events that the writer defines. In games the player can affect the events and their interpretation. There's also a visual aspect in games. It's like an interactive film. (boy, event 2, ID10)

Mostly coming up with the story [is interesting in games], to get the player interested in the game and its elements. I am also of course interested in programming even though I can't code. (girl, event 1, ID 05)

Attending a game jam increased interest in co-creative and creative projects in general (see also Meriläinen, 2019), with almost all of our participants reporting increased interest in creative activities, like graphic designing, creating visual novels, and scriptwriting. A few individual responses explicitly mentioned increased creativity as a result of the jam.

I think [the event] mainly intensified the desire to try writing and my own creativity with different platforms and in other fields. Writing manuscripts for games is one option, but script writers and playwrights are needed in many other projects as well. We survived this and even had fun, so the barrier to try something else new lowered. (girl, event 2, ID 20)

My technical skills expanded, I learned to use new tools, my creativity improved with new tools. (boy, event 1, ID 04)

\subsection{Social dimensions:"Best moments were good laughs with the team"}

Other people and perceptions of them formed a large part of the game jam experience both before and during the event. When asked what the participants expected of the game jam event, several participants said that they were eagerly waiting to meet new people. This was most emphasized in our first event, in which the participants came from three different schools. Attending the same school did not, however, mean that the participants know each other beforehand. For example, 
the schools of the last two jam events had 600-700 students. There were also mentions of getting to know new people through the jam.

I'm expecting new contacts. The main reason for me not playing games is that I do not have acquaintances who would be interested in games, so I hope to make new friends. I'm most nervous about not being useful or not getting anything done. (girl, event 1, ID 07)

Social anxiety can be a barrier to entry (Meriläinen \& Aurava, 2018). Before the jam event, some of our participants were apprehensive in regard to meeting new people or comparing their skills to other people's expected skill level, while some mentioned feeling nervous about the group work not being successful. Some also mentioned in the pre-jam survey that they did not feel close to the other students in their schools. For all of our respondents, fears about group work proved to be unfounded.

The success of the teamwork mainly [causes apprehension]. I do not feel close with several people in our school, and I am not sure how well we can for example settle on ideas that would suit everyone. (boy, event 3, ID 24, pre event survey)

Division of labor and group work worked out, because everyone had their own clear orientations. (boy, event 3, ID 24, post event survey)

Our group dynamics turned out to be surprisingly good. I went into the jam a little afraid of a mass of unknown people but once we finally got to form groups, to my surprise it wasn't all that terrible. Yay. In addition to this [I was surprised by the ease of] group work in such a short jam. Our shared mulling over resulted in something beautiful and it was a comforting experience. (boy, event 2, ID 11)

The positive expectations regarding meeting new people surpass the negative ones in our data. The desire to meet new like-minded people is perhaps more pronounced in adolescents than grown-ups (see Meriläinen \& Aurava, 2018). We did not observe any major disagreements during the events, nor did anyone mention them in the post-event surveys. The comments were all positive, stating that the teamwork had been fun and fulfilling.

In my opinion, teamwork went really well, we managed to deal out certain roles in our group and the atmosphere of the team was great. (boy, event 1 , ID 09)

Best moments were good laughs with the team, finishing the game at the last moment and it was also really nice to see all the games others made. The atmosphere in the jam was really relaxed and positive, which was likely partly due to the fact that everyone was experimenting, all in and with an open mind. (girl, event 2, ID 20)

Game testing and ideating [were best moments of the event] because during those moments one could properly talk with the whole team / other teams. (non-binary, event 3, ID 29) 
Social skills were not very often mentioned in the participant's learning goals, but they were the second most reported learning outcome. Game jams are usually collaborative efforts that require participants to negotiate and discuss many aspects of their game project, for example game content and workload sharing.

My social skills improved a lot during the short weekend. (girl, event 1, ID 07).

Time management skills developed as well as creative co-working skills. It is important to hear other people out and not just boss them around. (boy, event 2, ID 10)

\subsection{Technology: "Before the jam I thought I was completely clueless when it comes to programming"}

Of our participants, only a few claimed to have technical or IT skills before the event. More common was to perceive one's own technical skills as lacking or to state programming or other technical skills as learning goals for the jam. We addressed this by introducing a pre-jam workshop in the last two jam events. The workshops were voluntary, with the majority of jam participants taking part in the workshops. They lasted for two hours, and the participants were taught the basics of the game making software chosen as the recommended tool for that specific jam event (Twine for event 2, and Construct 3 for event 3).

Technical skills were furthered during the event, with several participants taking part in programming even though they had previously proclaimed they did not know how. After the jam event, the participants quite often mentioned they had learned technical skills, programming or using the software. Furthermore, there were several comments on programming or using the software being easier and more fun than anticipated.

Mostly my technical skills developed in a positive direction. Before, I had no experience in programming. Now, after I have taken the first step, I have searched YouTube for videos that teach programming. (boy, event 1, ID 08)

Taking up technical tasks during the jam seems to be gendered, with eight out of ten boys and two out of ten girls taking part in programming the games. However, the self-assessed learning of technical skills was more evenly distributed, with six boys and four girls claiming they had learned technical skills, programming or using the game creation software. All of the comments on programming being easier and more fun than anticipated were from girls or nonbinary students.

Before the jam I thought I was hopeless with computers and coding, but after the experience it feels pretty good and fun. (non-binary, event 3, ID 27)

Before the jam I was a bit nervous about how writing the script for the game will go, not to mention programming. Because of the time limits, the storyline of the game had to be narrowed pretty small, so there was no pressure to write a megalomaniacly fancy script and it was all more about having fun. Also, before the jam I thought I was completely clueless when it comes to program- 
ming, but I was surprised that the basics were not so hard (at least with Twine).

(girl, event 2, ID 20)

Programming being easier and more fun than anticipated connects to motivational beliefs such as proposed by Eccles et al., (1983, 1998), students' task-related enjoyment equaling intrinsic task value and as such, predicting further activities and even career plans later on. The math-related ability beliefs have also been connected to later STEM career outcomes (Ellis et al., 2016; Lazarides \& Lauermann, 2019; Seo et al., 2019). The notions of our participants that participating in the jam event made them realize they might not be as "clueless" or "hopeless" at programming as they previously thought may well be important personal breakthroughs for them.

\subsection{Personal relation to games and game culture: "I play because I'm interested in the art, music and ideas used in the games, and because it is fun"}

Games and game culture were an integral part of the participants' lives. All participants reported playing games in their free time, with the majority of participants playing frequently and identifying as gamers, and only a few reporting to play very little. This is in line with previous studies of Finnish gaming: of 10-19 years old Finns, $79 \%$ play digital games every week, $44.8 \%$ on a daily basis, with only $0.8 \%$ not playing digital games at all (Kinnunen et al., 2020). The few student participants in our events who played only a little showed some anxiety regarding their lack of experience.

I play because I' $m$ interested in the art, music and ideas used in the games, and because it is fun. I play when I feel like progressing in a game, for example to get better at a challenging game. (boy, event 1, ID 09)

Firstly I would like to get over the threshold that I've formed in relation to any digital game that is even a little complex. My parents have a slightly negative attitude towards gaming consoles, so I've never properly gotten into the world of digital games. (girl, event 2, ID 16)

Most of our participants played a wide variety of games, from live action role playing to board games. Several had designed or started to design their own games even before the jam event. Participation in game culture was more varied than playing or designing games: the participants reported other, game related hobbies and interests, such as drawing game related art, rehearsing voice acting, making and listening game music, boffering (playful fighting with soft, padded weapons), and learning programming in order to start making games. Our results are well in line with previous research on adolescents' metagaming activities that show game culture is more pervasive and diverse than just playing games, and can include discussing games, writing game reviews or fanfiction, drawing game characters and other game subjects, creating game videos, live streaming games, reading game-related books, and consuming game-related entertainment like eSports, gameplay videos and live streams (Kahila et al., 2020).

Our participants also wanted to learn more about games, and the wish to know how games are made, the process and the sub-areas of game making, was the most 
common learning goal reported in the pre-event surveys. Some participants also wanted to widen their perspectives regarding games and game culture in general. Furthermore, some participants hoped to find a job in the game industry.

I like playing games a lot and I have considered the game industry as a career as well. It would be great to do what I love. (boy, event 2, ID 09)

I would like to get to experience all steps of game making and the problems connected to them, and together with others to try and solve the possible problems. I believe that making a game in a game jam is a really great opportunity to get to learn everything that goes into making games. (boy, event 3, ID 24)

\section{Discussion}

Learning in itself can be motivating, and self-assessed learning is diverse, depending both on the participant's role in the team and on the nature and setting of the jam event. The majority of the participants in our jam events ended up practicing skills they did not possess before the event. In a school setting, where curricula define the learning goals, game jam learning might be overlooked because of the lack of specific subject matter. The broader goals of education, like communication and cooperation, are more generally achieved in game jamming. However, these are also the hardest to assess.

Creativity, in our data, was both a motivation to attend a game jam and, concurrently, attending game jams increased creativity. The co-creative process of game making attracted several participants to the jams but also caused some anxiety in others. In our jams, the invitation was phrased to underline the creative side and artistic tasks of making games and two of the jam events were arranged in schools specializing in art education, which plausibly highlights our results concerning creativity. Our participants often discussed their relation to games and game culture, whether they played a lot or felt like they did not play or know games enough. Games were seen as an essential part of culture, and as such, something worth knowing more about (see Meriläinen, 2020). Indeed, the desire to know more about what goes on behind the scenes of game making was a major motivation to attend a game jam. Our participants considered games to be a medium for self-expression, and a way to connect with the player.

Finding new like-minded contacts is a motivation to attend a game jam and attending game jams increases co-operational skills. For some, meeting new people can also cause stress before the event. In the post-event surveys only positive interactions were reported. When organising game jam events for adolescents, the social interactions should be properly addressed and supported. We have found that a workshop before the jam event, even if it is mostly marketed as an opportunity to learn the basics of the software, is also a good opportunity to alleviate any stress regarding the social factors. The workshop does not require being socially active, as it mostly concentrates on demonstrating how the software functions, but it gives the participants a chance to see who else is coming to the event. 
Based on our results, technology often causes pre-event anxiety, but learning how to code also appears to be a motivational factor to attend a game jam. Several participants reported learning programming or other technical skills. However, for girls and nonbinary students it was more common to state that programming was easier and more fun than anticipated, suggesting negative preconceptions of IT, but also that game jams can effectively erode the myth of programming being hard, especially if tools suitable for the participants are picked. This potentially means that game jams can increase girls' and nonbinary youth's participation in IT-related STEAM activities (see Fowler \& Schreiber, 2017), or at least lower the barriers to participation. For more specific information on how to organise more gender inclusive game jams, see (Aurava et al., 2021; Kerr et al., 2020).

Our results may seem contradictory in that girls and non-binary students rarely reported taking part in coding or using the game making software but still expressed changed attitudes towards those activities. One possible explanation is that they had participated in the workshop where the basics of that software had been taught, and the change in attitudes stems from there. It is also possible that working closely in a team and seeing their peers using that software changed their attitudes. Previous research also shows that girls have more negative self-concept in STEM subjects than boys (e.g. Gaspard et al., 2017; Jacobs et al., 2002; Nagy et al., 2010), and the change in attitudes could derive from initial negative self-concepts of girls and nonbinary students. Our findings support the idea that shifting from STEM to STEAM can attract a more gender-diverse group of participants in these activities (see Richard et al., 2015; Walan, 2021).

In terms of motivation, the themes described in the previous section highlight the diverse reasons our respondents participated in an educational game jam: they wanted to learn new skills (both technical and creative) and understand the process of game development, to make new friends and socialise, to express themselves through game creation. Many of the participants had a previous interest in games and wanted to engage with games from another perspective than as a consumer.

During our research project (anonymized for blind review), we have come to the conclusion that when jamming with adolescents without professional skills, as well as first-time jammers, the organisers should choose a software to be used in the game jam beforehand, and teach the basics of that software to the jammers, preferably a couple of days before the jam event. It helps reduce stress participants may have about their lacking technological skills, helps even out differences in technical skills and helps the participants to design and ideate a game by making them more familiar with the software and its functionalities and limitations. We strongly recommend organising pre-jam workshops regardless of the game development platform used, unless all participants are already known to be proficient.

Choosing a single platform to use in a jam also reduces the workload of the organisers: in a school-related game jam, the students often rely on someone being able to solve their problems and help with technical issues. If all students have learned to use the software, they can ask each other for help, and the organisers do not have to be proficient with multiple game making software. As our main goal has been to introduce game jamming to general education, we have also had to consider how to make jam events easy for teachers to organise (Aurava et al., 2021). We 
tried a variety of game development tools in our game jams, and found Twine and Construct 3 to be the best for our needs. These tools are free, easy to use, and do not require software to be installed. Easy-to-use tools helped balance differences in students' IT skills and helped them finish games during the limited time available, as less time was spent on learning to use the tools and more on actual game creation. The Unity platform we experimented with in our first game jam was found to be too challenging to grasp without previous experience, even with a specialist, an experienced game jammer proficient in the use of the platform, providing on-site assistance.

\subsection{Strengths and limitations}

The key strength of our study stems from its qualitative methods: the rich data consisting of responses formulated by young people themselves provides detailed information about game jams. The experiences reported by a diverse group of young game jammers in three different game jam events would have been very difficult to achieve using a quantitative approach. As it stands, the responses helped capture essential facets of not only game jamming, but young people's broader engagement with gaming cultures.

The limitations of this study connect to the context of the jam events and our own dual role as organisers and researchers. The jams events were organised in Finland, and although every one of them took place in a different major city (Tampere, Helsinki, and Turku), and in different schools with different themes and tools, we are still discussing a relatively homogenous group of students: all white, all studying in general upper secondary schools in major cities, with two of the jams organised in schools that specialize in performing art education. Although we have managed to treat the gender gap of participating in game design activities, there are several other demographic factors, like ethnicity or financial and educational background of the participants, that this study cannot address. In Finland, there is a larger societal problem of ethnic minorities or children with a lower socio-economic background not attending general upper secondary schools (see Finnish National Agency of Education, 2021b). To tackle these issues, we hope to do further game jam related research in either vocational schools or lower secondary schools, to reach a more diverse crowd of participants.

The sample size of the study is suitable for the methodology used, but limits the generalizability of the results. This is not a limitation as such, but instead a feature of qualitative research (e.g. Braun et al., 2020), as the knowledge produced is typically more detailed and nuanced rather than striving for more broad generalizations. However, our result can also serve as a starting point for quantitative methods, such as multiple-choice questionnaires, to see whether some of the findings reflect broader trends in educational game jamming.

Game jam events are unique, in that every event has their own theme and other restrictions. Thus, the game jams we organised are not similar but differ in many ways (e.g. locations, scheduling, tools, and themes), and running two of the jams in performing arts-focused schools may have increased the importance of the artistic 
and creative dimensions of educational game jamming. However, we feel confident that many of the themes we have brought up in this article, such as young people's apprehensions about trying a new activity and meeting new people, are both universal and relevant for others researching game jams or co-creative learning. This uniqueness of game jams makes longitudinal observations nearly impossible and it should be pointed out that the study captures the students' experiences in a certain time and situation, not over a longer period of time.

Being organisers in the events as well as researchers brings with it both positives and negatives: it is easier to know what the participants are referring to in the survey when we have been in the event ourselves, and the positive relationship between the researchers and participants may have helped produce lengthier and more mindful answers to the survey. On the other hand, our reading of the survey responses may be biased towards the positive. Our dual role may also have affected the participants' answers to our surveys: we have worked closely with them, and some of them might not have wanted to hurt our feelings by too harsh a critique-even with the responses being anonymous. The small group sizes also make it easier for us to know who has provided which answers, even without seeing the participant's name, so the anonymity is only relative.

The learning outcomes shown in our study are based on the self-assessments of the participants. Measuring learning is notoriously hard, and we did not have the resources to do that-furthermore, as learning in game jams is diverse, it would have been difficult to define what skills or knowledge would be measured and how. We also did not inquire after the success of the workshops we organised in conjunction with events 2 and 3. Although the observed participation rate was high we cannot know with certainty which participants to the jam events also attended the workshops and whether or not it affected their learning outcomes. In hindsight, we should have asked the participants their experiences and expectations after the workshop but prior to the jam event to see how effective workshops were in regard to alleviating the stress of lacking technical skills and social anxiety.

\subsection{Future research directions}

Our study presents several important and interesting directions and topics for further research. In addition to exploring which of the findings represent broader trends, future studies should look more closely into individual facets of educational game jamming. Examples of further exploration could be examining the impact of different game creation tools or settings on game jam outcomes, students' experiences of pre-jam workshops, and the differences in game jam experiences resulting from different jam durations.

The five-factor theory of personality (e.g. Costa \& McCrae, 1999) might also be of interest in the study of game jams, especially regarding learning and motivation (see e.g. Komarraju et al., 2011). In this study, we did not test our participants' personality traits, but from their open-ended answers we could for example make a hypothesis that the people who decide to attend a game jam event in their free time, would have high levels of Openness, Agreeableness, and Extraversion. 
In this study setting, the authors have been in a dual role of game jam organiser and game jam researcher. In future, we hope to continue studying game jams organised by teachers for their own students. It would affect both the positioning of the jam event as a school activity and possibly the data itself, since the students and researchers would not get acquainted during the event.

To include more diversity than just gender inclusivity, it would be important to study game jams in more varied educational surroundings. In Finnish context, it would mean organising game jams for younger kids still in primary or lower secondary education or broadening the scope from general to vocational upper secondary schools. International collaboration and repeating game jams in different school systems would also make the results more generalizable.

\section{Conclusions}

Game jams in a school context appear to be a valid working method for teaching and learning new skills as well as increasing students' self-confidence and their desire to learn more. Game jams do not ensure that every participant would learn the same things, as not everyone is practicing the same skills. In our events, where the games made were digital, the most often mentioned self-assessed learning results were programming or using game design software, co-operational skills, and time management skills. The learning results of game jams are in line with and can be seen as a viable method for learning twenty-first century skills. Taking part in a game jam challenged the participants' views of both their own skills and the difficulty of technology. Especially girls and non-binary game jam participants reported programming being easier and more fun than they previously had thought. Our results suggest that a school related jam event can be enjoyable and relaxed, without detracting from learning outcomes.

The findings of this study offer a variety of benefits to different stakeholders. For the game design industry that is hoping to get a more diverse workforce, our study offers a valuable lesson on how to frame game making and how to discuss game design activities. This is not trivial, since the discourse and the language we use can exclude or include individuals. For educators and school policy makers this study is a concrete example of the benefits of game jamming in schools. Organisers of game jam events, especially those aimed at adolescents, would benefit from our experiences and the feedback from our participants, to lower the threshold to attend a game jam. From a research point of view our study suggests several interesting and relevant topics for further studies, such as the gendered skill perceptions of potential young game jam participants and the goals, interests, personality traits and event qualities that promote or hinder game jam attendance.

Lastly, our study reveals something about young people's perceptions of games and gaming. They describe games as interactive art and outlet for creativity and self-expression, and view making games as an opportunity to provide people with experiences and to leave their mark in the world. While above we have discussed the utilitarian aspects of making games and organising game jams, it is important 
to keep in mind that providing young people with opportunities and tools to make games is valuable in itself.

\section{Appendix: Pre- and post-event surveys}

The original questionnaires were in Finnish. This is a translation by the authors. Pre-event survey:

Questions

Event \#

1. What kinds of games do you play? Why, when, and with whom?

1. What kinds of games do you play? Why, when, and with whom? Do you see yourself as a gamer?

2. What interests you in making games?

3. Tell us something about yourself: what kind of a person you are, what are your interests?

3.a) Tell us something about yourself: what kind of a person you are?

3. b) What are your hobbies? How do you spend your free time (by yourself, with friends or more formally)? What kinds of things do you find interesting?

4. What encouraged you to register to take part in this jam event?

5. Have you ever produced or designed a game or participated in a game jam? Have you taken part in other kinds of jam or hackathon events? Tell us about your experiences

5.a) Have you ever produced or designed a game of your own?

5.b) Have you ever participated in a game jam? Have you taken part in other kinds of jam or hackathon events? Tell us about your experiences

6. What kind of a role do you usually take in group work or projects?

7. Do you have prior experience of game making software or programming? Is there a software you would or would not like to use? Do you have any tools or software you could use in the jam event (e.g. Photoshop, drawing tablet, Garage Band, Unity)?

8. One can use several kinds of skills when creating games. What skills do you have for example in making graphics, writing, ideating, interaction, music, or programming?

9. In the jam event, would you like to work on a digital game or for example a board game or a card game? (This is not a final decision, we are just mapping the participants interests beforehand.)

10. What kind of help you might need while working on the game?

11. What are your hopes for the weekend? Is there something you are nervous about $\mathrm{x}$ before the event? [Note: The jam was organised during a weekend; the question refers to the jam event]

11. Is there something you are nervous about before the event?

12. What new things would you like to learn at the game jam?

13. Age

14. Gender: I am female/male/non-binary/other or do not want to tell

15. Class (how many years in general upper secondary school)

$\begin{array}{lll}1 & 2 & 3 \\ & & \\ & \mathrm{x} & \mathrm{x} \\ \mathrm{x} & \mathrm{X} & \mathrm{x} \\ & & \\ & \mathrm{x} & \mathrm{x} \\ \mathrm{x} & \mathrm{x} \\ & \mathrm{x} & \mathrm{x}\end{array}$

$\mathrm{X}$

$\begin{array}{ccc} & \text { X } & \text { X } \\ & \text { X } & \text { X } \\ & & \\ \text { X } & \text { X } & \text { X }\end{array}$

\section{$\mathrm{X}$}

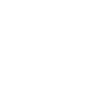

$\mathrm{X}$

x




\section{Post-event survey:}

Questions

Event \#

1. What did you end up doing in the jam? Was it something you had planned to do?

123

2. How did group work go in your team?

$\mathrm{X} \quad \mathrm{X}$

3. Did you ask for or receive help from other jam participants-from your own team $\mathrm{x}$ or others on site?

3. Did you ask for or receive help from other jam participants-from your own team, others on site, organizers? Did you help others? Describe the situations

4. Which of your skills were most useful in the jam? Did you realize something new $\mathrm{x}$ about your skills?

4.a) Which of your skills were most useful in the jam?

4.b) Compare your thoughts on your own skills before the jam and after it. How did your perceptions change during the jam?

5. Do you think your skills (e.g. co-operation, technical/artistic skills or time man- $\quad x$ agement skills) improved during the jam event?

5. Did your skills improve during the jam, e.g. co-operation, technical/artistic skills, time management skills, information retrieval skills, creativity, learning to learn etsc?

6. Was something easier than you had thought or vice versa?

7. Which moments of the event were the best, which were the worst? Why?

7.a) Which moments of the event were the best? Why?

7.b) Which moments of the event were the worst? Why?

8. How interested are you in participating in a game jam in the future?

9. How interested are you in making games in the future?

10. Did the jam event increase your willingness to learn or do something new? What?

11. Which aspects of the jam even and the practicalities would need to be changed? Which aspects were so well executed that they ought to be done similarly in future jam events?

12. You got study credits from participating in the jam. How much did that affect $\quad x$ your motivation to participate?

13. How would you describe your typical school performance?

13. How would you describe your typical school performance and motivation?

14. How interested are you in STEM (science, technology, engineering, maths) versus arts, as subjects taught in school?

15. What are your hobbies and why are you interested in them?

$\mathrm{X} \quad \mathrm{X}$

$\mathrm{X} \quad \mathrm{X}$

$\begin{array}{ccc} & \mathrm{X} & \mathrm{X} \\ & \mathrm{X} & \mathrm{X} \\ & \mathrm{X} & \mathrm{X} \\ & \mathrm{X} & \mathrm{X} \\ \mathrm{X} & \mathrm{X} & \mathrm{X} \\ & & \\ & \mathrm{X} & \mathrm{X} \\ & & \\ & & \end{array}$

16. What would you like to study or where would you like to work after general upper secondary school and why?

Acknowledgements The authors would like to thank the game jam participants and the collaborating teachers.

Authors' contributions Both authors contributed to the study conception and design. Material preparation, data collection and analysis were performed by both authors, and the manuscript was written by both authors. 
Funding This study was funded by the Academy of Finland, Strategic Research Counsil, project Growing Mind, grant number 312527.

Availability of data and material Due to the nature of this research, participants of this study did not agree for their data to be shared publicly, so supporting data is not available.

Code availability n/a.

\section{Declarations}

Ethics approval n/a.

Informed consent The informants of this study have given their informed consent to participate in the study.

Research involving human participants This study follows the ethical principles of research with human participants and ethical review in the human sciences in Finland, defined in the Finnish National Board on Research Integrity TENK guidelines 2019.

\section{Consent to participate $\mathrm{n} / \mathrm{a}$.}

\section{Consent for publication n/a.}

Conflicts of interest/Competing interests The authors have no conflicts of interest to declare that are relevant to the content of this article.

Open Access This article is licensed under a Creative Commons Attribution 4.0 International License, which permits use, sharing, adaptation, distribution and reproduction in any medium or format, as long as you give appropriate credit to the original author(s) and the source, provide a link to the Creative Commons licence, and indicate if changes were made. The images or other third party material in this article are included in the article's Creative Commons licence, unless indicated otherwise in a credit line to the material. If material is not included in the article's Creative Commons licence and your intended use is not permitted by statutory regulation or exceeds the permitted use, you will need to obtain permission directly from the copyright holder. To view a copy of this licence, visit http://creativecommons.org/licen ses/by/4.0/.

\section{References}

Ananiadou, K., \& Claro, M. (2009). 21st century skills and competences for new millennium learners in OECD Countries. OECD Education Working Papers, No. 41, OECD Publishing.

Arya, A., Chastine, J., Preston, J., \& Fowler, A. (2013). An international study on learning and process choices in the Global Game Jam. International Journal of Game-Based Learning, 3(4), 27-46. https://doi.org/10.4018/ijgbl.2013100103

Arya A., Gold S., Farber M., \& Miklasz K. (2019). GGJ-next: The global game jam for youth. ICGJ 2019: Proceedings of the International Conference on Game Jams, Hackathons and Game Creation Events 2019. https://doi.org/10.1145/3316287.3316289

Appianing, J., \& Van Eck, R. (2015). Gender differences in college students' perceptions of technologyrelated jobs in computer science. International Journal of Gender, Science and Technology, 7(1), 28-56.

Aurava, R., Kankainen, V., \& Murray, J. (2020a) Why won't they jam? The reasons for general upper secondary school students for not attending a game jam. Proceedings of the 9th Irish Conference on Game-Based Learning.

Aurava, R., Meriläinen, M., \& Stenros, J. (2020b). Teacher views on Game Jamming in General Formal Education. Proceedings of the 14th International Conference on Game Based Learning (ECGBL 2020). ACPI. 
Aurava, R., Meriläinen, M., Kankainen, V., \& Stenros, J. (2021). Game jams in general formal education. International Journal of Child-Computer Interaction, 28. https://doi.org/10.1016/j.ijcci.2021. 100274

Bailey, E. N., Miyata, K., \& Yoshida, T. (2021). Gender composition of teams and studios in video game development. Games and Culture, 16(1), 42-64. https://doi.org/10.1177/1555412019868381

Bequette, J. W., \& Bullitt Bequette, M. (2012). A place for art and design education in the STEM conversation. Art Education, 65(2), 40-47. https://doi.org/10.1080/00043125.2012.11519167

Binkley, M., Erstad, O., Herman, J., Raizen, S., Ripley, M., Miller-Ricci, M., \& Rumble, M. (2012). Defining twenty-first century skills. In P. Griffin, B. McGaw, \& E. Care (Eds.), Assessment and teaching of 21 st century skills (pp. 17-66). Springer.

Blikstein, P. (2013). Digital fabrication and 'making' in education: The democratization of invention. In C. Büching \& J. Walter-Herrmann (Eds.), FabLab: Of machines, makers and inventors (pp. 203222). Transcript.

Borg, M., Garousi, V., Mahmoud, A., Olsson, T., \& Stålberg, O. (2020). Video game development in a rush: A survey of the global game jam participants. IEEE Transactions on Games, 2(3), 246-259. https://doi.org/10.1109/TG.2019.2910248

Braun, V., \& Clarke, V. (2006). Using thematic analysis in psychology. Qualitative Research in Psychology, 3(2), 77-101. https://doi.org/10.1191/1478088706qp063oa

Braun, V., Clarke, V., Boulton, E., Davey, L., \& McEvoy, C. (2020). The online survey as a qualitative research tool. International Journal of Social Research Methodology. https://doi.org/10.1080/ 13645579.2020.1805550

Chen, Y., de la Mora, A., \& Kemis, M. (2017). Recruiting and retaining women in information technology programs: Practices and challenges in Iowa Community Colleges. New Directions for Community Colleges, 178, 79-90. https://doi.org/10.1002/cc.20255

Cheng, G. (2009). Using game making pedagogy to facilitate student learning of interactive multimedia. Australasian Journal of Educational Technology, 25(2), 204-220. https://doi.org/10.14742/ajet. 1150

Consalvo, M. (2008). Crunched by passion: Women game developers and workplace challenges. In Y. Kafai, C. Heeter, J. Denner, \& J. Y. Sun (Eds.), Beyond Barbie and Mortal Kombat (pp. 117-190). MIT Press.

Corneliussen, H. G., \& Prøitz, L. (2016). Kids Code in a rural village in Norway: Could code clubs be a new arena for increasing girls' digital interest and competence? Information, Communication \& Society, 19(1), 95-110. https://doi.org/10.1080/1369118X.2015.1093529

Costa, P. T., \& McCrae, R. R. (1999). A five-factor theory of personality. The Five-Factor Model of Personality: Theoretical Perspectives, 2, 51-87.

Cote, A. C., \& Harris, B. C. (2020). 'Weekends became something other people did': Understanding and intervening in the habitus of video game crunch. Convergence. https://doi.org/10.1177/13548 56520913865

Devedzic, V., Tomic, B., Jovanovic, J., Kelly, M., Milikic, N., Dimitrijevic, S., Djuric, D., \& Sevarac, Z. (2018). Metrics for students' soft skills. Applied Measurement in Education, 31(4), 283-296. https://doi.org/10.1080/08957347.2018.1495212

Dufva, T., \& Dufva, M. (2016). Metaphors of code - Structuring and broadening the discussion on teaching children to code. Thinking Skills and Creativity, 22, 97-110. https://doi.org/10.1016/j.tsc.2016. 09.004

Eberhardt, R. (2016). No one way to jam: Game ams for creativity, learning, entertainment, and research. Proceedings of the International Conference on Game Jams, Hackathons, and Game Creation Events (GJH\&GC'16) (pp. 34-37). https://doi.org/10.1145/2897167.2897181

Eccles, J. S., Adler, T. F., Futterman, R., Goff, S. B., Kaczala, C. M., Meece, J., et al. (1983). Expectancies, values and academic behaviors. In J. T. Spence (Ed.), Achievement and achievement motives: Psychological and sociological approaches (pp. 75-146). Freeman.

Eccles, J. S., Wigfield, A., \& Schiefele, U. (1998). Motivation to succeed. In N. Eisenberg (Ed.), Handbook of child psychology, 5(3) (pp. 1017-1095). Wiley.

Ellis, J., Fosdick, B. K., \& Rasmussen, C. (2016). Women 1.5 times more likely to leave STEM pipeline after calculus compared to men: Lack of mathematical confidence a potential culprit. PLoS One 11(7). https://doi.org/10.1371/journal.pone.0157447

European Union (2006). Recommendation of the European Parliament and of the Council of 18 December 2006 on key competences for lifelong learning. 2006/962/EC. Official Journal of the European Union, 2006. 
Faas, T., Liu, I., Dombrowski, L., \& Miller, A. D. (2019). Jam today, jam tomorrow: Learning in online game jams. Proceedings of the ACM on Human-Computer Interaction. ACM. https://doi.org/10. $1145 / 3361121$

Ferraz, C., \& Gama, K. (2019). A case study about gender issues in a game jam. Proceedings of the International Conference on Game Jams, Hackathons and Game Creation Events 2019. ACM. https:// doi.org/10.1145/3316287.3316290

Finnish Ministry of Education and Culture (2020). General upper secondary education. Ministry of Education and Culture. Retrieved from https://minedu.fi/en/general-upper-secondary-education on April 4th, 2021.

Finnish National Agency for Education (2021a). Publications and statistics. Retrieved from https://vipun en.fi/fi-fi/_layouts/15/xlviewer.aspx?id=/fi-fi/Raportit/Lukiokoulutus\%20-\%20opiskelijat\%20-\% 20kuukausittain.xlsb on September 28, 2021.

Finnish National Agency for Education (2021b). OECD comparison: Socio-economic background still a strong influence on educational choices - regional variations in Finland are small. Press release on September 17, 2021. Retrieved from https://www.oph.fi/en/news/2021/oecd-comparison-socioeconomic-background-still-strong-influence-educational-choices on October 5, 2021.

Ford, A., \& Kelly, S. (2016) Using game jams as a school transition event. Proceedings of the 10th European Conference on Game-Based Learning 2016. ACPI.

Fowler, A., \& Schreiber, I. (2017). Engaging under-represented minorities in STEM through game jams. ICGJ '17: Proceedings of the Second International Conference on Game Jams, Hackathons, and Game Creation Events. ACM. https://doi.org/10.1145/3055116.3055120

Fowler, A., \& Khosmood, F. (2018). The potential of young learners making games: An exploratory study. 2018 IEEE Games, Entertainment, Media Conference (GEM) (pp. 1-9). https://doi.org/10. 1109/GEM.2018.8516486

Fowler, A., Khosmood, F., Arya, A., \& Lai, G. (2013). The Global Game Jam for teaching and learning. Proceedings of the 4th Annual Conference of Computing and Information Technology Research and Education New Zealand, CITRENZ (2013), pp. 28-34

Fowler, A., Pirker, J., Pollock, I., Paula, B. C., Echeveste, M. E., \& Gómez, M. J. (2016). Understanding the benefits of game jams. Exploring the potential for engaging young learners in STEM. Proceedings of the 2016 ITiCSE Working Group Reports (pp. 119-135). ACM.

Gaspard, H., Häfner, I., Parrisius, C., Trautwein, U., \& Nagengast, B. (2017). Assessing task values in five subjects during secondary school: Measurement structure and mean level differences across grade level, gender, and academic subject. Contemporary Educational Psychology, 48.https://doi. org/10.1016/j.cedpsych.2016.09.003

Gibb, S. (2014). Soft skills assessment: Theory development and the research agenda. International Journal of Lifelong Education, 33(4), 455-471. https://doi.org/10.1080/02601370.2013.867546

Goddard, W, Byrne, R., \& Mueller, F. (2014). Playful game jams: Guidelines for designed outcomes. Proceedings of the 2014 Conference on Interactive Entertainment. ACM. https://doi.org/10.1145/ 2677758.2677778

Growing Mind (2021). Educational transformations for facilitating sustainable personal, social, and institutional renewal in the digital age. Retrieved from https://growingmind.fi/theproject/. Accessed 20 Oct 2021.

Hrehovcsik, M., Warmelink, H., \& Valente, M. (2016). The game jam as a format for formal applied game design and development education. In R. Bottino, J. Jeuring, \& R. C. Veltkamp (Eds.), Games and Learning Alliance (pp. 257-267). Springer International. https://doi.org/10.1007/9783-319-50182-6_23

Jacobs, J. E., Lanza, S., Osgood, D. W., Eccles, J. S., \& Wigfield, A. (2002). Changes in children's selfcompetence and values: Gender and domain differences across grades one through twelve. Child Development, 73(2), 509-527. https://doi.org/10.1111/1467-8624.00421

Kafai, Y. B. (2006). Constructionism. In K. Sawyer (Ed.), The Cambridge handbook of the learning sciences (pp. 35-46). Cambridge University Press.

Kafai, Y. B., \& Burke, Q. (2015). Constructionist gaming: Understanding the benefits of making games for learning. Educational Psychologist, 50(4). https://doi.org/10.1080/00461520.2015.1124022

Kahila, J., Tedre, M., Kahila, S., Vartiainen, H., Valtonen, T., \& Mäkitalo, K. (2020). Children's gaming involves much more than the gaming itself: A study of the metagame among 12- to 15-year-old children. Convergence. https://doi.org/10.1177/1354856520979482 
Kankainen, V., Kultima, A., \& Meriläinen, M. (2019). Motivations of game jam organizers: Case of Finnish game jam community. Proceedings of the 14th International Conference on the Foundations of Digital Games. ACM. https://doi.org/10.1145/3337722.3341840

Kennedy, H. W. (2018). Game jam as feminist methodology: The affective labors of intervention in the Ludic Economy. Games and Culture, 13(7), 708-727. https://doi.org/10.1177/1555412018764992

Kerr, A. (2020). Decoding and recoding game jams and independent game-making spaces for diversity and inclusion. In P. Ruffino (Ed.), Independent videogames: Cultures, networks, techniques and politics. Routledge advances in game studies (pp. 29-42). New York: Routledge.

Kerr, A., Savage, J., \& Twomey-Lee, V. (2020). Decoding and recoding game-making events for diversity, inclusion \& innovation. Maynooth University. Retrieved from http://mural.maynoothunivers ity.ie/12575/1/Kerretal.DecodingandRecodingGameMakingEvents2020final.pdf on 1 November 2020

Kerr, A., \& Savage, J. D. (2019). Spatial reasoning: Re-coding spaces for inclusive informal game making. Abstract proceedings of the 2019 DiGRA International Conference: Game, Play And The Emerging Ludo-Mix Digital Games Research Association (DIGRA).

Kerr, A., \& Savage, J. D. (2020). Hacking at the techno-feminist frontier - Gendered exclusion and inclusion in technology cultures. In P. Cullen \& M. Corcoran (Eds.), Producing knowledge, reproducing gender: Power, Production and Practice in Contemporary Ireland. Dublin: UCD Press.

Kinnunen, J., Taskinen, K., \& Mäyrä, F. (2020). Pelaajabarometri 2020: Pelaamista koronan aikaan. Tampere University. Retrieved on 1 November 2020 from http://urn.fi/URN:ISBN:978-952-03-1786-7

Komarraju, M., Karau, S. J., Schmeck, R. R., \& Avdic, A. (2011). The big five personality traits, learning styles, and academic achievement. Personality and Individual Differences, 51(4), 472-477. https:// doi.org/10.1016/j.paid.2011.04.019

Krajcik, J. S., \& Shin, N. (2014). Project-based learning. In R. K. Sawyer (Ed.), Cambridge handbook of the learning sciences (2nd ed., pp. 275-297). Cambridge University Press.

Kultima, A. (2015). Defining game jam. Proceedings of the 10th International Conference on the Foundations of Digital Games (FDG 2015).

Kultima, A. (2019). Superjammers: Motivations and experiences of exceptional game jammers in Finland. Proceedings of the International Conference on Game Jams, Hackathons and Game Creation Events 2019.https://doi.org/10.1145/3316287.3316295

Kultima, A., \& Sandovar, A. (2016). Game design values. Proceedings of Academic Mindtrek Conference 2016. New York: ACM. https://doi.org/10.1145/2994310.2994362

Kultima, A., \& Laiti, O. (2019). Sami game jam: Learning, exploring, reflecting and sharing indigenous culture through game jamming. Proceedings of the 2019 DiGRA International Conference: Game, Play And The Emerging Ludo-Mix Digital Games Research Association.

Kultima, A., Alha, K., \& Nummenmaa, T. (2016). Building Finnish game jam community through positive social facilitation. Proceedings of the 20th International Academic Mindtrek Conference. https://doi.org/10.1145/2994310.2994363

Land, M. H. (2013). Full STEAM ahead: The benefits of integrating the arts into STEM. Procedia Computer Science, 20, 547-552. https://doi.org/10.1016/j.procs.2013.09.317

Lavonen J., \& Korhonen T. (2017). Towards twenty-first century education: Success factors, challenges, and the renewal of Finnish education. In Choo S., Sawch D., Villanueva A., Vinz R. (Eds.), Educating for the 21st Century. Springer. https://doi.org/10.1007/978-981-10-1673-8_13

Lazarides, R., \& Lauermann, F. (2019). Gendered paths into STEM-related and language-related careers: Girls' and boys' motivational beliefs and career plans in math and language arts. Frontiers in Psychology, 10. https://doi.org/10.3389/fpsyg.2019.01243

Legault, M.-J., \& Weststar, J. (2017). Videogame developers among 'extreme workers'. Are death marches over? E-journal of International and Comparative Labour Studies, 6(3), 1-23.

Locke, R., Parker, L., Galloway, D., \& Sloan, R. J. S. (2015). The game jam movement: disruption, performance and artwork. Proceedings of the 10th International Conference on the Foundations of Digital Games (FDG 2015).

Lonka, K., Makkonen, J., Berg, M., Talvio, M., Maksniemi, E., Kruskopf, M., Lammassaari, H., Hietajärvi, L., \& Westling, S. K. (2018). Phenomenal Learning from Finland. Helsinki.

Makarova, E., Aeschlimann, B., \& Herzog, W. (2019). The gender gap in STEM fields: The impact of the gender stereotype of math and science on secondary students' career aspirations. Frontiers in Education, 10. https://doi.org/10.3389/feduc.2019.00060

Meriläinen, M. (2019). First-timer learning experiences in Global Game Jam. International Journal of Game-Based Learning, 9(1), 30-41. https://doi.org/10.4018/JJGBL.2019010103 
Meriläinen, M. (2020). Kohti pelisivistystä: Nuorten digitaalinen pelaaminen ja pelihaitat kotien kasvatuskysymyksenä. Kasvatustieteellisiä tutkimuksia. University of Helsinki, Faculty of Educational Sciences. http://urn.fi/URN:ISBN:978-951-51-5791-1

Meriläinen, M. \& Aurava, R. (2018). Internal barriers to entry for first-time participants in the Global Game Jam. Proceedings of the 12th European Conference on Games Based Learning (pp. 414421). ACPI.

Meriläinen, M., Aurava, R., Kultima, A., \& Stenros, J. (2020). Game Jams for Learning and Teaching: A Review. International Journal of Game Based Learning, 10(2), 54-71. https://doi.org/10.4018/ IJGBL.2020040104

Miller M., DeLuca J., \& Khosmood F. (2019). Can game jams boost confidence and sense of preparedness? ICGJ'19: Proceedings of the International Conference on Game Jams, Hackathons and Game Creation Events 2019. https://doi.org/10.1145/3316287.3316296

Nagy, G., Watt, H. M. G., Eccles, J. S., Trautwein, U., Lüdtke, O., \& Baumert, J. (2010). The development of students' mathematics self-concept in relation to gender: Different countries, different trajectories? Journal of Research on Adolescence, 20(2), 482-506. https://doi.org/10.1111/j.15327795.2010.00644.x

Neogames (2019). The game industry of Finland report 2018. Retrieved on 9th April 2021 from http:// www.neogames.fi/wp-content/uploads/2019/04/FGIR-2018-Report.pdf

OECD (2012). PISA 2012. Results in Focus. What 15-year-olds know and what they can do with what they know. Organization for Economic Co-operation and Development.

OECD (2013). Skilled for life? Key findings from the survey of adult skills. Organization for Economic Co-operation and Development

OECD. (2021). Education at a Glance 2021. OECD Publishing. https://doi.org/10.1787/b35a14e5-en.

Official Statistics of Finland (2020). Upper secondary general school education. Helsinki: Statistics Finland. Retrieved from http://www.stat.fi/til/lop/2019/lop_2019_2020-06-16_tau_001_en.html on 27th November, 2020.

Official Statistics of Finland (2021). Immigrants and integration. Retrieved from https://www.stat.fi/tup/ maahanmuutto/maahanmuuttajat-vaestossa/ulkomaan-kansalaiset_en.html on September 28. 2021.

Paavola, S., Lipponen, L., \& Hakkarainen, K. (2004). Modeling innovative knowledge communities: A knowledge-creation approach to learning. Review of Educational Research, 74, 557-576. https:// doi.org/10.3102/00346543074004557

Papert, S., \& Harel, I. (1991). Constructionism. Ablex Publishing Corporation.

Peppler, K., \& Kafai, Y. (2005). Creative coding: Programming for personal expression. Retrieved on 9th April 2021 from https://citeseerx.ist.psu.edu/viewdoc/download?doi=10.1.1.88.1191\&rep=rep1\& type $=$ pdf

Peticca-Harris, A., Weststar, J., \& McKenna, S. (2015). The perils of project-based work: Attempting resistance to extreme work practices in video game development. Organization, 22(4), 570-587. https://doi.org/10.1177/1350508415572509

Piro, J. (2010). Going from STEM to STEAM. Education Week, 29(24), 28-29.

Pollock, I., Murray, J., \& Yeager, B. (2017). Brain jam: STEAM learning through neuroscience-themed game development. Proceedings of the Second International Conference on Game Jams, Hackathons, and Game Creation Events. ACM. https://doi.org/10.1145/3055116.3055122

Prescott, J., \& Bogg, J. (2011). Segregation in a male-dominated industry: Women working in the computer games industry. International Journal of Gender, Science And Technology, 3(1).

Preston, J. A., Chastine, J., O’Donnell, C., Tseng, T., \& MacIntyre, B. (2012). Game jams: Community, motivations, and learning among jammers. International Journal of Game-Based Learning, 2(3), 51-70. https://doi.org/10.4018/ijgbl.2012070104

Richard, G. T., Kafai, Y. B., Adleberg, B., \& Telhan, O. (2015). StitchFest: Diversifying a College Hackathon to Broaden Participation and Perceptions in Computing. Proceedings of the 46th ACM Technical Symposium on Computer Science Education (pp. 114-119). ACM. https://doi.org/10.1145/ 2676723.2677310

Riikonen, S., Seitamaa-Hakkarainen, P., \& Hakkarainen, K. (2020). Bringing maker practices to school: Tracing discursive and materially mediated aspects of student teams' collaborative making processes. International Journal of Computer-Supported Collaborative Learning, 15, 319-349. https://doi.org/10.1007/s11412-020-09330-6

Romero, M., Lepage, A., \& Lille, B. (2017). Computational thinking development through creative programming in higher education. International Journal of Educational Technology in Higher Education, 14(1), 1-15. https://doi.org/10.1186/s41239-017-0080-z 
Savvani, S. (2020). Emotions and challenges during game creation: Evidence from the global game jam. Proceedings of the 14th European Conference on Games Based Learning. https://doi.org/10. 34190/GBL.20.063

Saw, G., Chang, C.-N., \& Chan, H.-Y. (2018). Cross-Sectional and Longitudinal Disparities in STEM Career Aspirations at the Intersection of Gender, Race/Ethnicity, and Socioeconomic Status. Educational Researcher, 47(8), 525-531. https://doi.org/10.3102/0013189X18787818

Scardamalia, M., \& Bereiter, C. (2014). Knowledge building and knowledge creation: Theory, pedagogy, and technology. In K. Sawyer (Ed.), The Cambridge handbook of the learning sciences (2nd ed., pp. 397-417). Cambridge University Press.

Seo, E., Shen, Y., \& Alfaro, E. C. (2019). Adolescents' Beliefs about Math Ability and Their Relations to STEM Career Attainment: Joint Consideration of Race/ethnicity and Gender. Journal of Youth and Adolescence, 48, 306-325. https://doi.org/10.1007/s10964-018-0911-9

Sigurðardóttir H.D.Í. (2020). Empowering women to seek careers in game development and creative IT Studies. In Pappas I., Mikalef P., Dwivedi Y., Jaccheri L., Krogstie J., \& Mäntymäki M. (Eds.) Digital transformation for a sustainable society in the 21st century. IFIP Advances in Information and Communication Technology, vol 573. Springer. https://doi.org/10.1007/978-3-030-39634-3_10

Smith, P. A., \& Bowers, C. (2016). Improving social skills through game jam participation. Proceedings of the International Conference on Game Jams, Hackathons, and Game Creation Events. ACM. https://doi.org/10.1145/2897167.2897172

Steinke, T., Linsenbard, M., Fiske, E., \& Khosmood, F. (2016). Understanding a Community: Observations from the Global Game Jam Survey Data. Proceedings of the International Conference on Game Jams, Hackathons, and Game Creation Events. ACM. https://doi.org/10.1145/2897167. 2897173

Trilling, B., \& Fadel, C. (2009). 21st century skills, enhanced edition: Learning for life in our times. Wiley.

Walan, S. (2021). The dream performance - a case study of young girls' development of interest in STEM and 21 st century skills, when activities in a makerspace were combined with drama. Research in Science \& Technological Education, 39(1), 23-43. https://doi.org/10.1080/02635143.2019.16471 57

Wearn, N., \& McDonald, B. (2016). Ethos of location and its implication to the motivators of Global Games Jam participants. Proceedings of the International Conference on Game Jams, Hackathons, and Game Creation Events. ACM. https://doi.org/10.1145/2897167.2897176

Yamane, S. R. (2013). Adaptability of the Global Game Jam: A case study in Japan. Proceedings of the 8th International Conference on the Foundations of Digital Games.

Publisher's note Springer Nature remains neutral with regard to jurisdictional claims in published maps and institutional affiliations. 